FACULTY OF BUSINESS ADMINISTRATION AND ECONOMICS

Working Paper Series

Working Paper No. 2021-10

Reviewing from a Distance: Uncovering the Negativity Bias of Psychological Distance in Online Word-of-Mouth

Jürgen Neumann, Dominik Gutt and Dennis Kundisch

May 2021 


\title{
Reviewing from a Distance: Uncovering the Negativity Bias of Psychological Distance in Online Word-of-Mouth ${ }^{1}$
}

\author{
Jürgen Neumann \\ Paderborn University \\ juergen.neumann@uni-paderborn.de
}

\author{
Dominik Gutt \\ Erasmus University Rotterdam \\ gutt@rsm.nl
}

\author{
Dennis Kundisch \\ Paderborn University \\ dennis.kundisch@uni-paderborn.de
}

May 6, 2021

\begin{abstract}
How does reviewing consumption experiences from a psychological distance affect one's online ratings? Prior literature has found a positivity bias in the reviewing behaviors of consumers when they evaluate an experience from a spatial or a temporal distance. However, these results do not fully account for the unique context of online reviews, which involves publicly associating oneself with a potentially negative experience in front of others. Analyzing a data set from a large review platform, which enables identification of reviewers' spatial and temporal distance, we found that the positivity bias is not present for consumption experiences that are characterized by a negative sentiment. Instead, ratings for negative experiences reviewed from a spatial distance-that is, reviews by travelers - are systematically lower than ratings given in spatial proximity — that is, reviews by locals. These findings can be attributed to spatial distance, enabling travelers to distance themselves from these experiences and thus publicly associate themselves with lower ratings. For temporal distance, we found patterns consistent with prior literature that highlighted a disparity between spatial and temporal distance. These results improve our theoretical understanding of reviewing behavior and help platforms in their efforts to de-bias ratings.
\end{abstract}

Keywords: Online Word-of-Mouth, Traveling, Psychological Distance, Construal Level, Self-Enhancement, SelfDistancing.

JEL Classification: M15, M31, O32, D12

\footnotetext{
${ }^{1}$ The authors thank participants at the 2017 International Conference on Information Systems (ICIS), the 2017 INFORMS Annual Meeting, the 2018 Symposium on Statistical Challenges in E-Commerce Research (SCECR), the 2017 Workshop of IS Design and Economic Behavior (ISDEB), and at research seminars at Paderborn University. The work was partially supported by the German Research Foundation (DFG) within the Collaborative Research Centre "On-The-Fly Computing” (SFB 901) under the project number 160364472-SFB901.
} 


\section{Introduction}

Research on psychological distance has had a tradition in psychology and marketing for the past two decades (Maglio, 2020). Psychological distance is defined as an "egocentric" perception of "the different ways in which an object might be removed" from "the reference point of self in here and now" (Trope and Liberman, 2010, p. 440). Psychological distance can be induced by spatial, temporal, social, or hypothetical distance between an object and the "here and now." Scholars have investigated the role of psychological distance in determining outcomes such as decision-making, persuasion, negotiation, creativity, and consumer evaluation (Trope et al., 2007; Huang et al., 2016; Stamolampros and Korfiatis, 2018).

The growing importance of digitized consumption evaluations in the form of online reviews has contributed to a rising interest in this concept by IS and marketing scholars. For example, prior research (Huang et al., 2016) has found positive effects of psychological distance on online ratings for restaurants, drawing on construal level theory. This work has primarily focused on spatial distance (how far a reviewer traveled to the restaurant) and temporal distance (how much time there is between the consumption experience and the review writing). The construal level theory-based reasoning applied by Huang et al. (2016) is that a higher spatial or temporal distance lends enchantment, and the reviewer focuses more on the positive dining experience, which increases online ratings. What this reasoning has not accounted for, however, is that psychological distance can be conductive to dealing with past negative events. In the sense that "time is a healer," increasing psychological distance facilitates sharing of negative events (Kross and Ayduk, 2017). In the online context, consumers often refrain from sharing negative experiences to protect their self-view (Angelis et al., 2012). Consequently, this study aims to answer whether psychological distance in the form of spatial and temporal distance supports consumers in articulating negative experiences online and results in lower ratings. Thus, our research question reads as follows: 
How does psychological distance in spatial and temporal dimension affect the online evaluations of negative consumer experiences? ${ }^{2}$

To answer this research question, we analyzed a TripAdvisor data set of 1,206,156 consumer reviews with varying degrees of psychological distance along the spatial and temporal dimension while considering the negativity of an experience as a moderator. In the next section, we review the relevant prior literature to contrast our contribution against that backdrop.

\section{Related Literature \& Contribution}

Huang et al. (2016) focused on the interaction between spatial and temporal distance. Using a data set from TripAdvisor, they found that with increasing spatial and temporal distance, online ratings increased. Their study revealed a boosting effect when spatial and temporal distance are present simultaneously. Stamolampros and Korfiatis (2018) confirmed the positive impact of spatial and temporal distance and their interaction with each other on data sets from TripAdvisor and Booking.com. They extended the findings of Huang et al. (2016) by incorporating social distance as measured by the cultural difference between the reviewer's home location and the reviewed business. Yet, none of these studies considered the moderating impact that a negative experience can have on online reviewing behavior.

Weingarten and Berger (2017) investigated the role of negativity or positivity in a more general setting of information sharing behavior. They found that people are more open to sharing experiences of positive events that are in the future. For example, people are more inclined to talk about a future St. Patrick's Day party than a past one. Yet people are less likely to talk about a future event when it is negatively connotated to them (e.g., not being able to pay rent) than when the event has happened in the past. Their underlying theoretical reasoning postulates that this relationship is driven by future events being more emotionally arousing than past ones. This study, however, is silent on how varying degrees of spatial and temporal distance toward past experiences shape the way people not only share but also evaluate negative events.

\footnotetext{
${ }^{2}$ Given the context of online reviews, social distance, defined as the distance between the focal person or group to another person or group, and hypothetical distance, defined as the difference between actual and hypothetical experiences (Trope and Liberman, 2010), are beyond the scope of our context.
} 
By answering the above research question, our study advances the current status quo of knowledge on psychological distance and consumer evaluations in three ways.

Negative Experiences Drawing on self-distancing theory, we focused on the effects of psychological distance on the evaluation of negative experiences. In addition to the positivity bias of psychological distance in ratings by travelers (Huang et al., 2016), our results suggest that for spatial distance, this bias is moderated by the negativity of the experience. More specifically, we found that high psychological distance in the spatial dimension leads to more negative ratings, if negative experiences are reviewed. Following media richness theory (Daft and Lengel 1986) and recent online review literature (Sadiq et al. 2021), we operationalized an event's negativity or positivity using the sentiments of the review texts.

Different Context While Weingarten and Berger (2017) established the differential role of negative and positive event experiences regarding whether people shared their experience, they also called for research that examines varying degrees of psychological distance and their impact on the content of word-of-mouth. Our study answered this call by analyzing a markedly different context. In our context, we examined real consumption experiences that were in spatial and temporal distance of varying degrees and analyzed how these distances manifest in a review's rating and use of specific language. In contrast, Weingarten and Berger (2017) focused on hypothetical consumption experiences that were not posted online and on the decision to share word-of-mouth for future versus past events. In this new context, we demonstrate that theorizing based on self-distancing is required to understand information sharing behavior and consumers' evaluations of experiences, different from Weingarten and Berger's (2017) focus on emotional arousal. Our theory angle contributes to our understanding of the online reviewing behavior of consumers, which constitutes a crucial undertaking of any online or offline business (Babić Rosario et al., 2016).

Differences Between the Impact of Spatial and Temporal Distance When focusing on negative experiences, we found opposing moderating relationships for spatial and temporal distance. We found a negativity bias when spatial distance increases but a positivity bias when temporal distance increases. Our analyses further reveal that the negativity bias can be traced to self-distancing theory, and the positivity bias is explained by construal level theory. These results enhance our understanding of the 
differential effects of psychological distance in consumer evaluations and inform scholars that a broader theoretical scope than previously assumed is necessary to explain the differences.

\section{Theoretical Background: Self-Enhancement and Self-Distancing}

Huang et al. (2016) and Stamolampros and Korfiatis (2018) demonstrated the positive effect of psychological distance on online rating valence through more abstract construal levels. These studies rely on the notion that higher psychological distance toward an event is associated with more abstract mental representations of it, or higher construal levels (Trope and Liberman, 2010). Below, we discuss self-enhancement and self-distancing theory as different theoretical angles to explain how psychological distance can affect consumers' sharing of negative events.

\subsection{Self-Enhancement Theory}

Self-enhancement is a central motive of online reviewing behavior (Hennig-Thurau et al., 2004). It emphasizes that, among other things, consumers share word-of-mouth online to enhance their selfimage in relation to other consumers. The theoretical foundation for this motive lies within selfenhancement theory (Shrauger, 1975), which postulates that individuals strive to maintain a positive self-view through their actions and statements (Brown et al., 1988). Individuals aim to enhance their self-view by attaching themselves to positive personal outcomes (Brown et al., 1988). In line with this, people tend to frame negative events in their favor (Blaine and Crocker, 1993). Consumers strive to enhance their self-worth by perceiving their purchase decisions as good and smart (Hogg and Michell, 1996; Bagozzi et al., 1992), and they share these positive experiences with others (Angelis et al., 2012). Consumers do not have a feeling of enhancement associated with a negative experience. The negativity of the shared experience undermines their self-image (Sedikides, 1993) and causes them to relive the experience in their minds and connect its sentiment to themselves (Kross et al., 2005). Therefore, consumers driven by the need to protect their self-view freely share word-of-mouth for positive consumption experiences but hesitate to share word-of-mouth for negative ones (Angelis et al., 2012). Not sharing negative experiences or framing them more positively is considered an act of self-protection. Most of the studies examining self-enhancement in the context of word-of-mouth have focused on whether consumers share word-of-mouth or refrain from doing so (Angelis et al., 2012, Hennig-Thurau 
et al., 2004). Prior research suggests that consumers uphold self-protecting measures when rating experiences or products. Framing one's own experience performance in a more positive light (Arkin and Maruyama, 1979) and assigning more positive traits to oneself and more negative ones to others (Brown et al., 1988) are examples for this tendency. When audiences are large, so is the need to selfprotect (Barasch and Berger, 2014). Self-protection is particularly important in online word-of-mouth settings because consumer's digitized ratings are freely accessible to a large audience (Hennig-Thurau et al., 2004). Following media richness theory (Daft and Lengel 1986), we theorize that consumers selfprotect mainly via the numerical rating they give to an experience, because ratings are easily interpretable by the reader and thus represent a signal to readers in established frames of reference $-\mathrm{a}$ 5-point scale. By contrast, review texts have higher information richness, are more nuanced but require more effort to understand for readers (Daft \& Lengel 1986). Therefore, we argue that sentiment is a good measure to determine whether an experience was positive or negative whereas the rating is the target for self-protection concerns. ${ }^{3}$

\subsection{Self-Distancing Theory}

According to self-distancing theory, individuals can take on two different perspectives when reflecting on an event (Kross and Ayduk, 2011). Taking on a self-immersed perspective, individuals relive the experience before their eyes (Kross and Ayduk, 2017). In this case, there is no difference between the self that remembers the experience and the self that has lived through the experience. In contrast, individuals taking on a self-distanced perspective observe the experience from a distance. In this case, there is a psychological distance between the remembering self and the experiencing self. Individuals who perceive experiences from a distance feel less distressed and are able to make meaning of their experiences (Kross and Ayduk, 2011). They also exhibit lower levels of emotional reactivity upon event perception from a self-distanced perspective (Kross et al., 2005; Kross and Ayduk, 2011; Kross and Ayduk, 2017; Mischkowski et al., 2012). Altogether, the findings of these studies imply that psychological distance helps individuals cope with and overcome negative events by separating the

\footnotetext{
${ }^{3}$ In section 5.3, we provide empirical evidence corroborating our assumption that review sentiment is, by and large, unchanged by psychological distance. This suggests that review sentiment is not the target of selfprotection concerns.
} 
experiencing from the remembering self. Consequently, we theorize that psychological distance eases the need to protect one's self-view from sharing such negative experiences. When one engages in selfdistancing, negative experiences hurt the psychologically distant experiencing self, but not—or to a lesser extent - the present remembering self. Hence, while writing a review, the remembering self has a lower need to self-protect because it can attach the negative experience to the experiencing self (Wojnicki and Godes, 2017). Therefore, our hypothesis reads as follows:

Hypothesis: The positive relationship between psychological distance and the rating valence is moderated by the negativity of the experience, so a negative sentiment weakens the relationship.

\section{Data}

We obtained data from TripAdvisor using a customized web crawler. Because restaurant visits are TripAdvisor's hallmark, we focused on those reviews in our study. For 4,436 cities of 1,042 US counties, we collected the full review history of all restaurants located there. Similar to Huang et al. (2016), we leveraged traveling behavior by reviewers as a measure for spatial distance as well as the difference in dates between review and consumption experience as a measure for temporal distance. From all restaurant reviews in the data set, we included only those reviewers who came from the cities whose review history we obtained. In this way, in line with prior literature (Kokkodis and Lappas, 2020), we ensured variation in traveling activity and could observe each reviewer's behavior in the absence of spatial distance. We excluded any reviews prior to 2012 because those did not include information on the date of the restaurant visit. Our final data set included 1,206,156 individual reviews posted by 163,224 reviewers who rated 88,065 different restaurants between 2012 and 2020. Table 1 reports the summary statistics of our data set. We obtained the valence of a rating (RATING) and the rating history of all the reviewers for the restaurants of our sample. Based on this, we computed a reviewer's average rating (REVIEWER_AVG_RATING) and a reviewer's review count (REVIEWER_NUM_REV) at the time of review. Using the complete review history of a business (including reviews prior to 2012), we computed its average rating (BUSINESS_AVG_RATING) and its number of reviews (BUSINESS_NUM_REV) at the time of review. 
Table 1: Summary Statistics

\begin{tabular}{|l|l|l|l|l|l|}
\hline \multicolumn{2}{l}{ N } & Mean & Std. Dev. & Min & Max \\
\hline RATING & $1,206,156$ & 4.156 & 1.033 & 1 & 5 \\
\hline NEGATIVITY & $1,206,156$ & 0.669 & 0.226 & 0 & 2 \\
\hline TRAVEL_DIST & $1,206,156$ & 375.274 & 787.081 & 0 & 11,896 \\
\hline LN_TRAVEL_DIST & $1,206,156$ & 3.152 & 2.835 & 0 & 9 \\
\hline MONTH_DIFF & $1,206,156$ & 1.389 & 2.110 & 0 & 12 \\
\hline LN_MONTH_DIFF & $1,206,156$ & 0.656 & 0.590 & 0 & 3 \\
\hline BUSINESS_NUM_REV & $1,206,156$ & 47.025 & 98.999 & 0 & 1,709 \\
\hline BUSINESS_AVG_RATING & $1,206,156$ & 3.903 & 1.072 & 0 & 5 \\
\hline REVIEWER_NUM_REV & $1,206,156$ & 13.219 & 46.910 & 0 & 2,106 \\
\hline REVIEWER_AVG_RATING & $1,206,156$ & 3.640 & 1.516 & 0 & 5 \\
\hline NOIE: FOr & &
\end{tabular}

Note: For first-time reviewers, REVIEWER_NUM_REV and REVIEWER_AVG_RATING are 0. Similarly, when restaurants receive their first review, $B \bar{U} S I N E S S \_N U M \_R E V$ and $B U S I N E S S \_A V G \_R A T I N G$ equal 0.

\subsection{Main Variables}

Sentiment First, we needed to determine the sentiment of the consumption experience. Using a textual analysis, and specifically the rule-based sentiment analysis VADER (Hutto and Gilbert 2014), allowed us to determine whether the consumption experience was overall negative. VADER, an established method to determine the sentiment valence and sentiment intensity of user-generated texts in online environments, has been successfully used to analyze online reviews (Du et al. 2019). Instead of relying on lexicons to determine the sentiment, this method incorporates additional rules to improve its validity. For instance, by considering tri-grams in review texts, the tool determines whether a word is associated with a negation and flips the sentiment valence of the word accordingly. By using the VADER implementation of the Natural Language Toolkit (Bird et al., 2009), we determined a sentiment score between -1 and 1 for each sentence of a review. Sentiment intensity is high for values close to -1 and 1 , respectively. We calculated the average sentiment for a review by taking the average over the sentiment scores from all sentences. We took the inverse of this scale to obtain a measure for the negativity of a consumption experience (NEGATIVITY). Further, for ease of model interpretability, we transformed the scale of this variable to $[0,2]$ by adding a 1 . Values close to 2 represent a strongly negative sentiment, and values close to 0 or 1 indicate a strongly positive or neutral sentiment, respectively.

As expected, NEGATIVITY exhibits a strong negative correlation with RATING. The corresponding correlation coefficient is -0.5049 . 
Spatial Distance Second, to capture spatial distance, our focal driver of psychological distance, we obtained the longitude and latitude for the center of each reviewer's home location and each restaurant location using the MapQuest API. Using these coordinates, we calculated the geodesic distance between each pair of cities (Picard, 2010). This calculation accounts for the spheric surface of the earth based on great circle distance (Vincenty, 1975) and provides a measure in kilometers (TRAVEL_DIST). Owing to the skewness in its distribution and in keeping with prior literature (Huang et al., 2016), we logtransformed this variable after adding 1 to ensure that reviews by locals (defined as a reviewer who posts a review in their home location) were not dropped from the data set due to this transformation (LN_TRAVEL_DIST).

Temporal Distance Third, we introduced a complementary measure for psychological distance, which is focused on temporal distance. Because reviewers indicate the month and year of their visit on TripAdvisor, we were able to calculate a measure for temporal distance directly from our data. Following Huang et al. (2016), we calculated the difference in months between the date of review publication and the date of visit $\left(M O N T H_{-} D I F F\right)$. Again, due to the skewness of this variable's distribution, we log-transformed it after adding $1\left(L N \_M O N T H \_D I F F\right)$.

\subsection{Empirical Method}

To test our hypothesis, we analyzed the relationship between psychological distance and the valence of online ratings using a regression analysis. We employed the following model:

$$
\begin{aligned}
\text { RATING }_{i j t}= & \beta_{0}+\beta_{1} L N_{-} T R A V E L_{-} D I S T_{i j t}+\beta_{2} N E G A T I V I T Y_{i j t} \\
& +\beta_{3} L N_{-} M O N T H_{-} D I F F_{i j t}+\beta_{4} L N_{-} T R A V E L_{-} D I S T_{i j t} x \text { NEGATIVITY } \\
& +\beta_{5} L N_{-} M O N T H_{-} D I F F_{i j t} x \text { NEGATIVITY } \\
& +\zeta X_{i t}+\zeta Z_{j t}+\delta_{i}+\varphi_{j}+\theta_{t}+\epsilon_{i j t}
\end{aligned}
$$

$\operatorname{RATING}_{i j t}$ represents the rating valence of reviewer $i$ 's rating for business $j$ in month $t$. The coefficient $\beta_{1}$ describes the base relationship between spatial distance and one's rating, regardless of negativity. Following prior literature, we expected to find a statistically significant positive value for the estimate of $\beta_{1}$ due to the positivity bias of psychological distance. The coefficient $\beta_{2}$ describes the base relationship between a negative sentiment and ratings regardless of the reviewer's psychological distance. $\beta_{3}$ represents the base relationship between temporal distance, regardless of negativity, and 
ratings for which we would expect a positive relationship. Finally, the coefficients $\beta_{4}$ and $\beta_{5}$ represent our coefficients of interest, which capture the relationship between psychological distance with a negative sentiment and one's rating. Per our theorizing, we expected to observe a statistically significant and negative estimate for these coefficients.

$X_{i t}$ and $Z_{j t}$ are vectors of reviewer-level (REVIEWER_NUM_REV and REVIEWER_AVG_RATING) and business-level (BUSINESS_NUM_REV and BUSINESS_AVG_RATING) control variables that serve as proxies of a reviewer's time-variant reviewing tendencies and expertise as well as a restaurant's time-variant popularity and quality. In particular, controlling for the business's average rating prior to consumption accounts for differences in expectations that may arise from selecting a specific restaurant, as demonstrated by Yin et al. (2016). Moreover, Schoenmueller et al. (2020) validated that the number of reviews by reviewer $i$ prior to visiting reviewing business $j$ serves as an effective proxy to control for rating polarity-related self-selection into reviewing. We followed this approach and incorporated REVIEWER_NUM_REV to safeguard against systematic differences of reviewers to self-select into reviewing a particularly negative or positive experience that could bias our focal coefficients.

Because of additional obstacles in the identification of this relationship in our analysis, we implemented multiple fixed effects. First, we needed to rule out that time-invariant unobserved heterogeneity between the populations of travelers and locals biased our results. To do that, we introduced reviewer-level fixed effects $\left(\delta_{i}\right)$ and leveraged within-reviewer differences in their local and travel ratings. These fixed effects account for a reviewer's general positivity in their ratings and for their general writing style. Second, to rule out that our results were biased by time-invariant unobserved heterogeneity between restaurants - because low-quality restaurants may aim for one-shot interactions with tourists-we introduced restaurant-level fixed effects $\left(\varphi_{j}\right)$. Third, to account for possible seasonal effects in the ratings for restaurants, we used monthly and yearly fixed effects $\left(\theta_{t}\right)$. Finally, $\epsilon_{i j t}$ represents the random error term.

NEGATIVITY controls for several self-selection concerns raised about travelers picking systematically different restaurants at home than while traveling. On the one hand, some travelers may be prone to visiting tourist traps — offering a negative experience - that they would not fall prey to in their home 
location. On the other hand, travelers might explore high-class dining venues while traveling that they would never indulge in at home. NEGATIVITY ensures that the sentiment of restaurant experiences at home and while traveling is comparable and complements our control variable REVIEWER_NUM_REV in mitigating this potential concern.

\section{Empirical Results}

\subsection{Baseline Results}

We estimated our multiway fixed effects regressions using the package REGHDFE for Stata (Correia, 2019). Table 2 presents our baseline results. In columns (1) and (2), we estimate the model of equation (1) by exclusively accounting for either temporal distance or spatial distance, respectively. Column (3) presents the coefficient estimates for the model of equation (1). Reassuringly, we found a statistically significant and negative association between NEGATIVITY and RATING, which supports the validity of our operationalization for the consumption experience's sentiment. An increase in negative sentiment by 1 in the review text is associated with an average decrease of 2.15 stars in rating valence.

Interestingly, we found heterogenous relationships for the two types of psychological distance we investigated. The statistically significant positive estimate for $L N_{-} T R A V E L_{-} D I S T$ and the statistically significant negative estimate for its interaction with NEGATIVITY support our hypothesis. According to our results in column (3), a $100 \%$ increase in spatial distance is, on average, associated with an increase in rating valence by 0.0208 stars for a strongly positive experience $($ NEGATIVITY $=0)$. For a strongly negative experience (NEGATIVITY $=2$ ), the results suggest an increase by only 0.008 stars, suggesting a moderating role of negative experiences. However, the coefficients corresponding to temporal distance contrast these findings. For neutral to negative experiences (NEGATIVITY>1), the coefficient estimates suggest a positive association between temporal distance and rating valence, which coincides with prior findings. This relationship grows stronger with an increase in negativity. For positive relationships, we found the opposite.

These results suggest that prior literature has presented an incomplete picture of the impact of psychological distance on consumer evaluations. First, the positivity biases of spatial distance and 
temporal distance highly depend on the experience's sentiment. Second, the moderating role of sentiment differs between these two psychological distances.

Table 2: Baseline Regression Results

\begin{tabular}{|c|c|c|c|}
\hline & (1) Spatial & (2) Temporal & (3) Both \\
\hline Variable & RATING & RATING & RATING \\
\hline \multirow{2}{*}{$L N \_T R A V E L \_D I S T x$ NEGATIVITY } & $-0.0133 * * *$ & & $-0.0064 * * *$ \\
\hline & $(0.00156)$ & & $(0.001578)$ \\
\hline \multirow{2}{*}{$L N \_T R A V E L \_D I S T$} & $0.0268 * * *$ & & $0.0208 * * *$ \\
\hline & $(0.00105)$ & & $(0.00106)$ \\
\hline \multirow{2}{*}{$L N \_M O N T H \_D I F F \times$ NEGATIVITY } & & $0.224 * * *$ & $0.219 * * *$ \\
\hline & & $(0.00686)$ & $(0.00695)$ \\
\hline \multirow{2}{*}{$L N \_M O N T H \_D I F F$} & & $-0.226 * * *$ & $-0.219 * * *$ \\
\hline & & $(0.00448)$ & $(0.00452)$ \\
\hline \multirow{2}{*}{ NEGATIVITY } & $-2.005 * * *$ & $-2.204 * * *$ & $-2.150 * * *$ \\
\hline & $(0.00674)$ & $(0.00694)$ & $(0.0101)$ \\
\hline Control Variables & $\checkmark$ & $\checkmark$ & $\checkmark$ \\
\hline Reviewer-level FE & $\checkmark$ & $\checkmark$ & $\checkmark$ \\
\hline Business-level FE & $\checkmark$ & $\checkmark$ & $\checkmark$ \\
\hline Month-and year-level FE & $\checkmark$ & $\checkmark$ & $\checkmark$ \\
\hline Observations & $1,206,156$ & $1,206,156$ & $1,206,156$ \\
\hline Adj. $R^{2}$ & 0.425 & 0.426 & 0.427 \\
\hline
\end{tabular}

Note: Robust standard errors are in parentheses. ${ }^{*} \mathrm{p}<0.1{ }^{*{ }^{* *}} \mathrm{p}<0.05{ }^{* * *} \mathrm{p}<0.01$.

Because we found support for our theorizing in the case of spatial distance, we further investigated its role for consumer evaluations. In our data set, reviewers might not have perceived spatial distance because they were not reviewing from their home location. For instance, they might have directly reviewed the restaurant after their meal using their mobile phone. Therefore, we aimed to ensure that reviewers posted their reviews from their home location. Intuitively, with a sufficiently high temporal distance toward the consumption experience, consumers would be more likely to write the review from their home location. To this end, we restricted our sample to those reviews that were written with a temporal distance of at least 1 month. The corresponding results in Table 3 suggest that negativity both moderates the relationship between spatial distance and rating valence as well as changes the sign of this relationship. More specifically, for a negativity larger than 1.582 or 1.65 (columns (1) and (2), respectively), the results suggest a negative association between spatial distance and rating valence. 
Table 3: Regression Results for Sample Restricted to Reviews with a Temporal Distance Greater Than or Equal to 1 Month

\begin{tabular}{|c|c|c|}
\hline & (1) Spatial & (2) Both \\
\hline Variable & RATING & RATING \\
\hline \multirow{2}{*}{ LN_TRAVEL_DIST $x$ NEGATIVITY } & $-0.0201 * * *$ & $-0.0172 * * *$ \\
\hline & $(0.00193)$ & $(0.00196)$ \\
\hline \multirow{2}{*}{ LN_TRAVEL_DIST } & $0.0321 * * *$ & $0.0280 * * *$ \\
\hline & $(0.00131)$ & $(0.00132)$ \\
\hline \multirow{2}{*}{$L N \_M O N T H \_D I F F \times$ NEGATIVITY } & & $0.150 * * *$ \\
\hline & & $(0.0103)$ \\
\hline \multirow{2}{*}{$L N \_M O N T H \_D I F F$} & & $-0.236 * * *$ \\
\hline & & $(0.00676)$ \\
\hline \multirow{2}{*}{ NEGATIVITY } & $-1.883 * * *$ & $-2.038 * * *$ \\
\hline & $(0.00814)$ & $(0.0141)$ \\
\hline Control Variables & $\checkmark$ & $\checkmark$ \\
\hline Reviewer-level FE & $\checkmark$ & $\checkmark$ \\
\hline Business-level FE & $\checkmark$ & $\checkmark$ \\
\hline Month- and Year-level FE & $\checkmark$ & $\checkmark$ \\
\hline Observations & 802,834 & 802,834 \\
\hline Adj. $R^{2}$ & 0.418 & 0.421 \\
\hline
\end{tabular}

Note: Robust standard errors are in parentheses. ${ }^{*} \mathrm{p}<0.1 ;{ }^{* *} \mathrm{p}<0.05 ;{ }^{* * *} \mathrm{p}<0.01$.

\subsection{Theoretical Mechanism: How Travelers Distance Themselves}

In this section, we conduct textual analyses to investigate the underlying theoretical mechanism of selfdistancing and shed more light on the heterogeneity of our results regarding spatial and temporal distance.

The Role of Self-Referential Language: Per our theoretical background, we hold self-distancing responsible for our focal relationship. This implies that reviewing from a psychological distance should lead reviewers to associate the review with their distant experiencing self rather than their current remembering self. In the following analysis, we present empirical evidence for this mechanism.

A key aspect of self-distancing theory is how individuals refer to themselves. They can either refer to themselves from a first-person or a non-first-person perspective and this translates into their use of language. Prior literature has established that people who use first-person words when reporting their experiences take on a more self-immersed perspective; by contrast, people using non-first-person words take on a more self-distanced perspective (Kross and Ayduk, 2017). A number of experiments have analyzed how self-talk - the act of talking about experiences somebody made themselves - is associated with self-distancing. (For an overview, see Kross and Ayduk, 2017.) For instance, 
individuals using non-first-person pronouns are more likely to remember negative experiences from a distant observer's perspective than individuals using first-person pronouns (Kross et al., 2014). These individuals exhibit less emotional reactivity for negatively arousing pictures when they are associated with their name than those using first-person pronouns do (Moser et al., 2017). Asking people to use either first- or non-first-person language can be a stimulus to nudge them into a self-immersed (firstperson) or self-distanced (non-first-person) perspective, as experimental results have shown (Kross and Ayduk, 2017). Altogether, these findings establish that using less self-referential language, or fewer first-person pronouns, is closely tied to self-distancing. In the context of our study, we expected travelers who reviewed experiences with a negative sentiment to use fewer first-person pronouns in their reviews than travelers reviewing positive experiences. That is because travelers feel an increased psychological distance to their consuming self, which allows them to self-distance when reviewing negative experiences. They would rather describe their experience with more non-first-person language ("The food was awful") than first-person pronouns ("I hated the food").

To this end, we employed the Linguistic Inquiry and Word Count (LIWC) (Pennebaker et al., 2015) to measure the usage of first-person pronouns in reviews. LIWC has been scientifically evaluated (Kahn et al., 2007; Pennebaker et al., 2015) and used to measure emotions in texts. It has also been used to analyze online reviews (Yin et al., 2016). For any given text in the English language, this dictionarybased tool provides, among several other variables, two variables for the occurrence of first-person singular and first-person plural pronouns that indicate the share of these words. Based on its validated dictionary, the tool analyzes each word in a text to determine whether it is a first-person pronoun in the singular ("I," "me," "mine") or in the plural ("we," "us," our") and adjusts the output variable accordingly. By taking the sum of the shares of first-person pronouns in the singular and in the plural, we created a new variable, $S E L F \_R E F$, as a measure for self-referential language.

We used $S E L F \_R E F$ as a dependent variable instead of $R A T I N G$ in our baseline model. According to self-distancing theory, we would expect to find negative sentiments negatively moderating the relationship between spatial distance and self-referential language. The estimated coefficient for LN_TRAVEL_DIST $x$ NEGATIVITY in Table 4 is both statistically significant and negative. The estimates suggest that, compared to travelers reviewing positive experiences, those reviewing negative 
ones use fewer references to the self in their review texts. These findings support the existence of selfdistancing as a central driver of our results. Again, for the case of temporal distance, we found the opposite, suggesting that there is another theoretical mechanism at play, which we further investigate next. Additionally, we also find that reviewing negative experiences from a psychological proximity is associated with more references to the self (see coefficient for NEGATIVITY), which further supports the notion that psychological distance supports taking on a self-distanced perspective.

Table 4: Self-Referential Language as Dependent Variable

\begin{tabular}{|c|c|}
\hline & $(1)$ \\
\hline Variable & $S E L F \_R E F$ \\
\hline \multirow{2}{*}{ LN_TRAVEL_DIST $x$ NEGATIVITY } & $-0.0526 * * *$ \\
\hline & $(0.00516)$ \\
\hline \multirow{2}{*}{$L N \_T R A V E L \_D I S T$} & $0.134 * * *$ \\
\hline & $(0.00379)$ \\
\hline \multirow{2}{*}{$L N \_M O N T H \_D I F F x$ NEGATIVITY } & $0.158 * * *$ \\
\hline & $(0.0232)$ \\
\hline \multirow{2}{*}{$L N \_M O N T H \_D I F F$} & $-0.310 * * *$ \\
\hline & $(0.0166)$ \\
\hline \multirow{2}{*}{ NEGATIVITY } & $1.695 * * *$ \\
\hline & $(0.0280)$ \\
\hline Control Variables & $\checkmark$ \\
\hline Reviewer-level FE & $\checkmark$ \\
\hline Business-level FE & $\checkmark$ \\
\hline Month-and year-level FE & $\checkmark$ \\
\hline Observations & $1,206,156$ \\
\hline Adj. $R^{2}$ & 0.291 \\
\hline
\end{tabular}

The Role of Construal Level: One explanation for the differences in our findings between temporal distance and spatial distance could be that the results corresponding to the former are explained by construal level theory (Trope and Liberman, 2010), consistent with the findings of Huang et al. (2016). Previous research has shown that individuals' construal is reflected in their use of language (Semin and Smith, 1999), with specific words indicating either concreteness (low construal) or abstractness (high construal). To determine the construal level in review texts, we employed two measures, which we used as dependent variables in a re-estimation of our baseline model. 
For our first measure, we relied on the dictionary compiled by Brysbaert et al. (2014), which provides concreteness ratings by the 4,000 participants of their study for 40,000 English lemmas ${ }^{4}$. Each lemma was rated on a scale from 1 (abstract) to 5 (concrete) by up to 30 participants recruited via Amazon Mechanical Turk. Prior research has employed this dictionary to show how temporal distance affects the construal level of tweets on Twitter (Bhatia and Walasek, 2016) and how spatial and temporal distance affect concreteness of online review texts (Stamolampros and Korfiatis, 2018). For each word of each review in our data set, we obtained the average concreteness score per this dictionary. We determined its part of speech using TreeTagger (Schmid, 1999) and then obtained its lemma using the Wordnet Lemmatizer (Miller, 1995) of the Natural Language Toolkit (Bird et al., 2009). For each review, we calculated an overall average concreteness score, which we then used as a dependent variable (column (1) in Table 5).

For our second measure, we used the Linguistic Category Model, or LCM (Semin et al., 2002). LCM has been used to analyze the relationship between different psychological distances and abstract construal (Trope and Liberman, 2010). For instance, the model has been used to show that spatial distance increases construal level (Fujita et al., 2006). The LCM provides a classification scheme that assigns each text a value from 1 (concrete representation) to 5 (abstract representation) to indicate its construal level. The basic intuition is that each word belongs to a category, which indicates a certain level of abstractness. The following formula presents how the construal level can be calculated (Semin et al., 2002):

$$
L C M s c o r e=\frac{(D A V+2 \cdot I A V+3 \cdot S V+4 \cdot A D J E C T I V E+5 \cdot N O U N)}{(D A V+I A V+S V+A D J E C T I V E+N O U N)}
$$

The variables in equation 2 represent the frequencies of each word category in the given text. Consequently, ADJECTIVE and NOUN are the number of adjectives and nouns, respectively. The variables $D A V, I A$, and $S V$ describe the number of different types of verbs-namely, descriptive action verbs (e.g., "call," "kick"), interpretive action verbs (e.g., "cheat," "help"), and state verbs (e.g., "admire," "hate"). To calculate the LCMscore as in equation (2), we determined whether each word in

\footnotetext{
${ }^{4}$ Lemmas are dictionary forms of words. Each word can be reduced to its dictionary form. For instance "goes" and "going" share the same lemma—namely, "go."
} 
the review was a noun, adjective, verb, or none of these, and then we classified each verb into a category. Huang et al. (2016) pointed out that determining the LCMscore manually with human coders is complex and time-consuming. Therefore, we followed the approach proposed by Seih et al. (2017), who developed a dictionary consisting of 7,489 verbs with their corresponding LCM category. Again, using TreeTagger (Schmid, 1999) to identify nouns, adjectives, and verbs from a given sentence, and the dictionary by Seih et al. (2017) to identify the category for verbs, we calculated the LCMscore for each review text in our data set by counting the number of words for each category. We excluded verbs in the review texts if they had not been categorized by Seih et al. (2017). We incorporated the LCMscore as a dependent variable in our baseline model (column (2) in Table 5).

The results in column (1) of Table 5 suggest that, for negative experiences, increased spatial distance is associated with increased concreteness - a lower construal level—which contradicts the predictions of construal level theory. We, in fact, found a decrease in concreteness - a higher construal level—for the interaction between negativity and temporal distance, which is in line with construal level theory. Similarly, considering the results in column (2) regarding construal level indicated by the LCMscore, we did not find a statistically significant relationship for the interaction between spatial distance and negativity, but we noted a positive relationship with respect to the interaction between temporal distance and negativity. Overall, this supports our reasoning that, for negative experiences, the positive relationship between temporal distance and ratings is in line with predictions by construal level theory, whereas the negative relationship between spatial distance and ratings is in line with self-enhancement and self-distancing theory. 
Table 5: Construal Level as Dependent Variable

\begin{tabular}{|l|l|l|}
\hline \multicolumn{2}{|l}{$(1)$} & \multicolumn{2}{l}{$(2)$} \\
\hline Variable & Brysbaert Score & LCMscore \\
\hline \multirow{2}{*}{ LN_TRAVEL_DIST x NEGATIVITY } & $0.0018^{* * *}$ & 0.00062 \\
\cline { 2 - 3 } & $(0.000300)$ & 0.000434 \\
\hline \multirow{2}{*}{ LN_TRAVEL_DIST } & $-0.0005^{* *}$ & $-0.000704 * *$ \\
\cline { 2 - 3 } & $(0.000220)$ & $(0.000347)$ \\
\hline \multirow{2}{*}{ LN_MONTH_DIFF } & $-0.0136^{* * *}$ & $0.00947^{* * *}$ \\
\cline { 2 - 3 } & $(0.00135)$ & $(0.00221)$ \\
\hline \multirow{2}{*}{ NEGATIVITY } & $-0.00581^{* * *}$ & $-0.0120^{* * *}$ \\
\cline { 2 - 3 } & $(0.00097)$ & $(0.00155)$ \\
\hline Control Variables & $0.05119^{* * *}$ & $-0.303 * * *$ \\
\hline Reviewer-level FE & $(0.00165)$ & $(0.00264)$ \\
\hline Business-level FE & $\checkmark$ & $\checkmark$ \\
\hline Month- and year-level FE & $\checkmark$ & $\checkmark$ \\
\hline Observations & $\checkmark$ & $\checkmark$ \\
\hline Adj. R ${ }^{2}$ & $\checkmark$ & $\checkmark$ \\
\hline Note: Robust SITY & $1,206,156$ & $1,206,156$ \\
\hline
\end{tabular}

Note: Robust standard errors are in parentheses. ${ }^{*} p<0.1 ;{ }^{* *} p<0.05 ;{ }^{* * *} p<0.01$.

\subsection{Robustness Checks}

In this section, we present robustness checks with respect to (1) the propensity to post negative reviews,

(2) differences in the sentiment intensity between travelers and locals, and (3) self-selection for certain restaurants. Additional robustness checks apart from the ones presented in this section are in Table A1 in the appendix.

Propensity to Post Negative Reviews Even though we used a three-way fixed effects approach and Schoenmueller et al.'s (2020) control variable for polarity-related self-selection into reviewing, there could be lingering endogeneity concerns about spatially distant reviewers having a higher propensity to post negative reviews than locals. This might explain our negativity bias of travelers. To mitigate this concern, we mimicked a decreased likelihood to post negative reviews and assess whether it changes the moderation of rating and spatial distance by negativity. In particular, we identified the subgroup of spatially distant reviewers who gave reviews with negative sentiment. We reduced the number of this subgroup in an iterative simulation. To this end, we used a binary definition of traveling and negativity. We let the variable TRAVEL be 1 if a reviewer posted a review for a restaurant outside of their home county to ensure at least some level of psychological distance for each traveler. We also let the variable 
NEGATIVE be 1 if NEGATIVITY was larger than 1 . Because of our simulation analysis, we would expect the coefficient of the interaction term TRAVEL $x$ NEGATIVE to remain similar in magnitude, sign, and statistical significance if the moderating relationship were not driven by an increased likelihood of negative travelers to leave a review. Our exact simulation procedure was as follows: We under-sampled the population of negative travelers by increments of $2.5 \%$, starting with an undersampling rate of $u=2.5 \%$ and ending at $u=80 \%$. For each $u$, we randomly under-sampled negative travelers 100 times and estimated our baseline model after each under-sampling. Thus, for each $u$, we obtained 100 estimates of TRAVEL $x$ NEGATIVE. We computed the average of the 100 coefficient estimates and standard errors for each $u$ and plotted them in Figure 1.

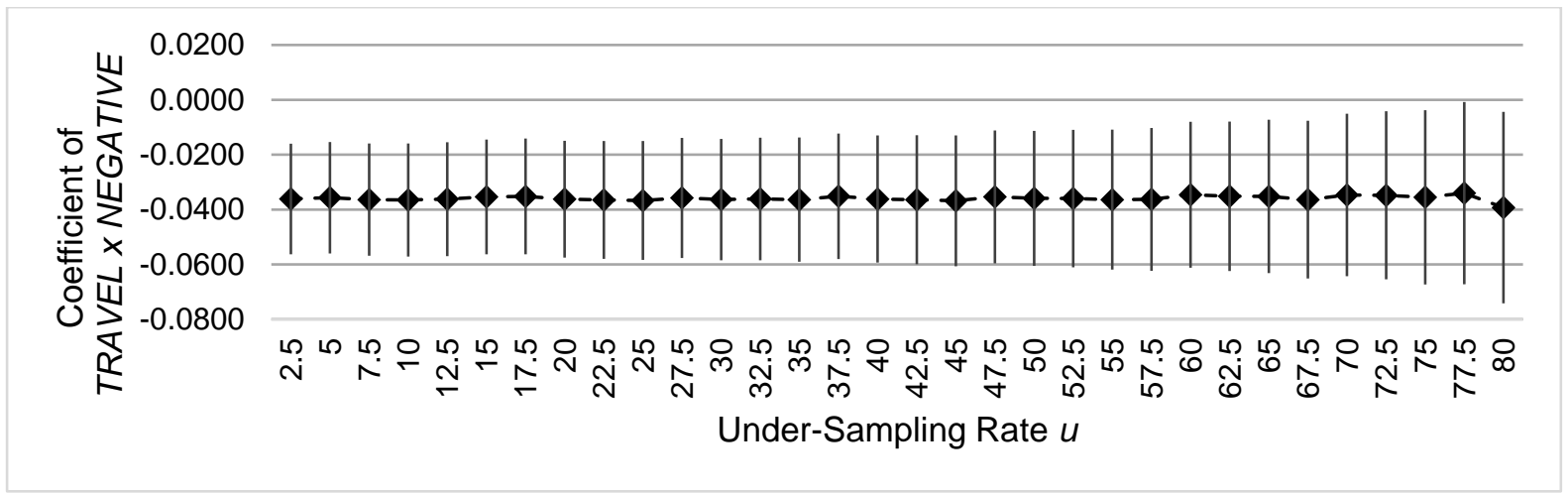

Figure 1: Under-Sampling of Negative Travelers

As depicted in this figure, the coefficient of TRAVEL $x$ NEGATIVE remains qualitatively unchanged from our baseline results and stable over all values of $u$. This suggests that our focal estimate is not driven by an increased likelihood of travelers to post a negative review. Based on these results, we reasoned that the negativity bias is not driven by whether to share a negative review but rather how low the rating will be, which is in line with our theorizing.

Differences in the Sentiment Intensity Between Travelers and Locals: As suggested by construal level theory, travelers should be more likely to focus on the positive aspects of their restaurant visit (Williams et al., 2014) and thus give more positive ratings. Additionally, self-distancing helps individuals experiencing negative emotions (Kross and Ayduk, 2017). Following these notions, an alternative theoretical explanation for our results could be that, for a given rating, travelers exhibit a more positive sentiment in their review texts than locals do. To examine this notion, we introduced 
NEGATIVITY as a dependent variable into our fixed effects regression while controlling for rating. The results suggest that travelers, on the contrary, exhibit a slightly more negative sentiment (coefficient for $L N \_T R A V E L \_D I S T$ of 0.001 ). This suggests that the above theorizing cannot explain our results. ${ }^{5}$

We wanted to further address the potential concern that sentiments between travelers and locals might be systematically different for similar experiences. This concern is most pertinent for experiences that are rather neutral and not clear-cut negative or positive. Therefore, we removed those reviews exhibiting a sentiment score close to 1 . According to Hutto and Gilbert (2014), reviews with a sentiment score between -0.05 and +0.05 around the neutrality threshold are neither negative nor positive. Second, we restricted our sample to those reviews exhibiting a clearly negative or a clearly positive sentiment score by only considering the lowest and highest $10 \%$ of reviews in terms of negativity. We expected these clearly positive and negative experiences to be perceived as such, regardless of whether one was a traveler or a local. Reassuringly, in both re-estimations of our baseline model for these samples, we found qualitatively unchanged results.

Self-Selection for Certain Restaurants: One of our endogeneity concerns was the self-selection of travelers for certain restaurants. Travelers might go to different restaurants when traveling than they usually patronize at home, which cannot be captured using restaurant fixed effects. One might be concerned that going to different restaurants results in factors biasing the traveler's rating that are not accounted for by controlling for the sentiment. We addressed this concern in two ways.

First, we restricted our sample only to restaurants belonging to a chain, ensuring that restaurants visited at home and while traveling were of similar quality. Furthermore, this accounted for expectations because consumers generally know what to expect from a restaurant belonging to a specific chain. Using a list of 256 restaurant chains in the US, we checked whether each restaurant in our data set contained the name of a chain (e.g., restaurants named "Applebee's Grill + Bar" is considered part of "Applebee's"). We restricted our sample to those reviews concerning a chain restaurant. Further, we incorporated reviewer-chain fixed effects to account for time invariant preferences of a reviewer for a specific chain. Reviewer-chain fixed effects effectively ensured that we only considered reviewers who

\footnotetext{
${ }^{5}$ We thank an anonymous reviewer for this suggestion.
} 
frequented the same chain at least twice at varying degrees of spatial and temporal distance. Again, we found that spatial distance is also associated with a negativity bias in ratings for negative experiences (NEGATIVITY>0.89) (see Table 6).

Table 6: Sample Restricted to Restaurants Belonging to Chains

\begin{tabular}{|l|l|}
\hline \multirow{2}{*}{ Variable } & $(1)$ \\
\hline \multirow{2}{*}{ LN_TRAVEL_DIST x NEGATIVITY } & $-0.0344^{* *}$ \\
\cline { 2 - 2 } & $(0.0153)$ \\
\hline \multirow{2}{*}{ NN_TRAVEL_DIST } & $0.0306^{* * *}$ \\
\cline { 2 - 2 } & $(0.0111)$ \\
\hline \multirow{2}{*}{ LN_MONTH_DIFF $x$ NEGATIVITY } & $0.282^{* * *}$ \\
\cline { 2 - 2 } LN_MONTH_DIFF & $(0.0688)$ \\
\hline \multirow{2}{*}{ NEGATIVITY } & $-0.195^{* * *}$ \\
\cline { 2 - 2 } & $(0.0489)$ \\
\hline Control Variables & $-1.780^{* * *}$ \\
\hline Reviewer-Chain FE & $(0.0860)$ \\
\hline Month- and Year-level FE & $\checkmark$ \\
\hline Observations & $\checkmark$ \\
\hline Adj. R ${ }^{2}$ & $\checkmark$ \\
\hline $\begin{array}{l}\text { Note: Robust standard errors are in parentheses. }{ }^{*} p<0.1 ;{ }^{* *} p<0.05 ; \\
\text { p } p .01 .\end{array}$ & 15,869 \\
\hline
\end{tabular}

Second, to completely rule out this concern regarding self-selection, we would ideally have run an experiment assigning reviewers to comparable restaurants at home and while traveling. Naturally, this is not possible. To mimic this experiment, we aimed to conduct $k$-means Jaccard clustering (Leisch 2006) to identify clusters of very similar restaurants based on their attributes. Therefore, we make use of another data set containing restaurant reviews posted on the review platform Yelp. We obtained the data directly from Yelp in the course of the ninth round of their data set challenge (see Yelp 2021). Using a customized web crawler we additionally collected reviewers' home locations as indicated in their Yelp profile. For this analysis, we considered spatial distance as traveling activity between the metropolitan areas in the data set, namely Las Vegas, NV, Madison, WI, Phoenix, AZ, Pittsburgh, PA, and Urbana-Champaign, IL. Because there is fewer variation in travel distance when measuring spatial distance on a metropolitan area level, we also introduced a binary measure for spatial distance and define the variable TRAVEL to be equal to 1 if a review has been posted for a restaurant outside of the 
reviewer's home metropolitan $\operatorname{area}^{6}$. Again, to ensure variation in traveling activity, we excluded all the reviewers who have, as observed in our data set, exclusively reviewed either within their home metropolitan area or while traveling. To ensure that the results of this analysis are also not driven by restaurants that are visited solely by locals or by travelers, we also remove these specific restaurants from our sample. The final set includes a total of 153,566 individual reviews posted by 6,895 different reviewers who rated a total of 12,225 different restaurants in 48 different cities between 2007 and 2017. Using this data set, we estimated a model similar to our baseline model. As presented in Table 7, we find qualitatively unchanged results, which demonstrates that our results hold across different review platforms.

Table 7: Baseline Model on the Yelp Data Set

\begin{tabular}{|c|c|}
\hline & $(1)$ \\
\hline Variable & RATING \\
\hline \multirow{2}{*}{ TRAVEL $x$ NEGATIVITY } & $-0.169 * * *$ \\
\hline & $(0.0403)$ \\
\hline \multirow{2}{*}{ TRAVEL } & $0.216^{* * *}$ \\
\hline & $(0.0289)$ \\
\hline \multirow{2}{*}{ NEGATIVITY } & $-2.555^{* * *}$ \\
\hline & $(0.0146)$ \\
\hline Control Variables & $\checkmark$ \\
\hline Reviewer-level FE & $\checkmark$ \\
\hline Business-level FE & $\checkmark$ \\
\hline Month-and Year-level Fixed Effects & $\checkmark$ \\
\hline Observations & 153,566 \\
\hline Adj. $R^{2}$ & 0.455 \\
\hline
\end{tabular}

While this additional data set does not contain information on the temporal difference between consumption and review publication, it provides a multitude of variables such as the availability of WiFi or the ambience as voted by the restaurant's visitors. We use these variables for our clustering approach (see Table A2 in the appendix). After applying standard scree plots to determine the optimal number of restaurant clusters (see Figure A1 in the appendix), we ended up with six clusters. We ran the above model specification separately for each of the six restaurant clusters with only those reviewers and

\footnotetext{
${ }^{6}$ The results remain qualitatively unchanged if we use a continuous measurement for spatial distance between the metropolitan areas.
} 
businesses that exhibit within-cluster variation in $T R A V E L^{7}$. Table 8 displays the results of these analyses, showing that the coefficients for TRAVEL and TRAVEL $x$ NEGATIVITY remained qualitatively unchanged. As an alternative approach to account for restaurant heterogeneity, we re-ran the model specification presented in Table 7 while restricting the sample to either (1) restaurants with the same category assigned by Yelp (e.g., Traditional American Restaurants, Italian Restaurants) or (2) restaurants with the same price category assigned by Yelp - the website offering 4 different price categories. The results remained qualitatively unchanged.

Table 8: Subsample Analysis with Restaurant Clusters

\begin{tabular}{|c|c|c|c|c|c|}
\hline & (1) & (2) & (3) & (4) & $(5)$ \\
\hline Variable & RATING & RATING & RATING & RATING & RATING \\
\hline \multirow{2}{*}{ TRAVEL $x$ NEGATIVITY } & $-0.316^{*}$ & 0.0636 & $-0.224 * * *$ & -0.0808 & -0.0605 \\
\hline & $(0.171)$ & $(0.250)$ & $(0.0806)$ & $(0.0923)$ & $(0.149)$ \\
\hline \multirow{2}{*}{ TRAVEL } & $0.259 * *$ & 0.189 & $0.276^{* * *}$ & $0.123^{*}$ & 0.104 \\
\hline & $(0.117)$ & $(0.180)$ & $(0.0567)$ & $(0.0678)$ & $(0.110)$ \\
\hline \multirow{2}{*}{ NEGATIVITY } & $-2.360 * * *$ & $-1.948 * * *$ & $-2.555 * * *$ & $-2.474 * * *$ & $-2.352 * * *$ \\
\hline & $(0.108)$ & $(0.140)$ & $(0.0336)$ & $(0.0392)$ & $(0.0737)$ \\
\hline Control Variables & $\checkmark$ & $\checkmark$ & $\checkmark$ & $\checkmark$ & $\checkmark$ \\
\hline Reviewer-level Fixed Effects & $\checkmark$ & $\checkmark$ & $\checkmark$ & $\checkmark$ & $\checkmark$ \\
\hline Business-level Fixed Effects & $\checkmark$ & $\checkmark$ & $\checkmark$ & $\checkmark$ & $\checkmark$ \\
\hline Month- and Year-level Fixed Effects & $\checkmark$ & $\checkmark$ & $\checkmark$ & $\checkmark$ & $\checkmark$ \\
\hline Observations & 4,644 & 2,246 & 31,743 & 26,061 & 7,901 \\
\hline Adj. $\mathrm{R}^{2}$ & 0.380 & 0.450 & 0.454 & 0.432 & 0.435 \\
\hline
\end{tabular}

Note: Robust standard errors are in parentheses. ${ }^{*} \mathrm{p}<0.1{ }^{* * *} \mathrm{p}<0.05 ;{ }^{* * * *} \mathrm{p}<0.01$.

\section{Discussion}

Our goal was to deepen the understanding of how psychological distance manifests in online ratings. By combining self-enhancement theory with self-distancing theory, we introduced a novel perspective on the impact of psychological distance on consumer evaluations that augments the established approach of prior literature (Huang et al., 2016; Stamolampros and Korfiatis, 2018) of applying construal level theory and stems from the self-protection-inducing nature of the online context. In an empirical study using online reviews from TripAdvisor (and Yelp), we found that reviewing from a spatial distance is associated with a negativity bias for experiences characterized by a negative

\footnotetext{
${ }^{7}$ Results remain unchanged without this restriction.
} 
sentiment. These results were driven by spatial distance lowering the need for self-protection, indicated by their use of fewer self-referential words.

\subsection{Contribution to Theory}

This study provides novel insights to research on online reviews and on psychological distance in three major ways.

Negative Reviews: Whereas prior research on the role of psychological distance for online ratings consistently presented findings suggesting a positivity bias of spatial distance (Huang et al., 2016; Stamolampros and Korfiatis, 2018), our study differentiates that role depending on the experience's sentiment. Our differentiation uncovered a negativity bias in online ratings given in spatial distance that exists alongside the positivity bias found in previous work. With the development of our theoretical framework featuring self-enhancement theory and self-distancing theory, we aimed to provide a conceptualization that accounts for this context and show that the negativity bias of spatial distance also corresponds to the use of fewer self-referential words. We found that the positivity bias of temporal distance grows stronger with the negativity of the experience and that, in line with construal level theory, the abstractness indicated in the review text increases. However, in further contrast to construal level theory, we found that, for positive experiences, there is a negative association between temporal distance and online ratings. This suggests that the overall positive association of temporal distance reported in prior work was predominantly driven by higher ratings given to negative dining experiences, in the sense that consumers focus on the negative experience abstractly (e.g., dining with friends) and neglect the details of the experience that annoyed them (e.g., rude waiters).

Context: This research answers the call from prior work to investigate how varying degrees of psychological distance relate to one's sharing of consumption experiences and the content of word-ofmouth (Weingarten and Berger, 2017). We contributed insights from real (as opposed to hypothetical) consumption experiences that were evaluated in varying degrees of spatial and temporal distance in the past (as opposed to the future), that were publicly displayed (as opposed to privately communicated), and that were evaluated on a rating scale (as opposed to shared versus not shared). In this way, we expanded on the theorizing of Weingarten and Berger (2017), who argued for differing levels of arousal 
between events happening in the past and the future while holding the psychological distance to these events constant. We found that varying degrees of psychological distance induce differing levels of selfprotecting behavior.

Differences Between Spatial and Temporal Psychological Distance: We uncovered a divergent impact of different dimensions of psychological distance when dealing with negative experiences. This finding goes beyond the commonly held belief that different psychological distance dimensions have a uniform effect on evaluations, as in the construal level theorization. Multiple studies show a "common currency" of psychological distance, meaning that the different dimensions of psychological distances are mentally conceptualized in the same way (Parkinson et al., 2014; Maglio et al., 2013). However, there is also evidence of differential effects of these dimensions (Zhang and Wang, 2009; Stamolampros and Korfiatis, 2018). Specifically, Zhang and Wang (2009) found that spatial distance significantly affects the impact of other dimensions of psychological distances, stating that spatial distance is more tangible than the other dimensions and that spatial distance is often used to mentally represent them. (For example, a socially distant person is represented as spatially far away in one's mind.) Drawing on these findings, Maglio (2020) called for more research revealing differential effects of psychological distances. By tracing down self-distancing as a theoretical mechanism responsible for the negative moderation of spatial distance but not for temporal distance, we have contributed to the call from prior research and enhanced the conceptual understanding of the interplay between psychological distances and consumer evaluation. With our results, we have also contributed to self-distancing theory. Even though prior research has shown that people can actively distance themselves by imagining a larger temporal distance between them and an experience (Bruehlman-Senecal and Ayduk, 2015), the majority of research (Kross et al., 2005; Kross and Ayduk, 2011; Mischkowski et al., 2012) has conceptualized self-distancing using spatial distance, such as imagining the experience as a "distant observer" or a "fly on the wall." This also holds for spontaneous self-distancing (Ayduk and Kross, 2010; White et al., 2019), which is arguably at play in our study. Consequently, our results suggest that spatial distance better supports individuals with spontaneously distancing themselves from negative experiences than temporal distance does. 


\subsection{Implications for Practice}

Given the importance of online reviews for consumer decision-making, and thus the success of online review platforms for local businesses, this study has important implications for the overall market outcomes and the design of these platforms. Because the valence of online ratings causally leads to higher sales (Babić Rosario et al., 2016) and increased pricing power (Feng et al., 2019), biases in online review systems can substantially affect market performance. Because consumers cannot reliably identify biases and account for them in decision-making, biased ratings can reduce consumer surplus (Hu et al., 2017). Consequently, both the positivity and the negativity bias of spatial distance can impede consumer decision-making.

With knowledge of the differential role of these biases, platform designers can adjust their review system accordingly and facilitate consumer decision-making. By either adding further metrics (e.g., number of travelers, flagging traveler reviews) or de-biasing the average rating (as suggested by Kokkodis and Lappas, 2020), they can respond to deteriorations in market outcomes stemming from these biases and prevent decreases in consumer surplus. Platform designers should account for these biases in their review elicitation strategies. For instance, Google asks consumers for reviews after they have navigated to a business using Google Maps (Carney 2019). In such a case, the platform needs to be aware that ratings are systematically different depending on the current geographical location at the time of elicitation.

In a similar way, based on the results of prior literature (Huang et al., 2016, Stamolampros and Korfiatis, 2018), sellers might actively aim to elicit reviews by travelers expecting a positivity bias. Our results suggest that this strategy could backfire. We expect our findings to carry over to other online contexts that induce individuals with self-enhancing and self-protecting behavior, such as social networks like Twitter or Facebook (Vargo et al., 2019). Following our results, tweets posted in spatial distance to an event should systematically differ in their content from those posted in spatial proximity depending on whether the event is generally positive or negative. Therefore, social media analytics should account for these biases in their analyses. 


\subsection{Limitations and Future Research Directions}

Naturally, this study has limitations that can open up avenues for future research. First, even though our reliance on focal constructs derived from review texts entailed several advantages, it also had some drawbacks. With the data available, we could not observe the consumer's feelings during the experience and had to rely on sentiments reported in the review text. Although it is reasonable to expect that the direction of an experience's sentiment persists until the time of review writing (in other words, an awful restaurant experience is unlikely to be viewed as an overall positive experience at the time of writing), there may be finer nuances of the experience that we could not measure. Second, although we used granular data on spatial and temporal distance, we could not exactly determine the reviewers' location during the time of writing. Despite our robustness checks, some travelers could have reviewed the restaurant directly after the experience. In this case, little spatial and temporal distance was present. These limitations represent natural avenues for future research.

\section{Conclusion}

This study advances the understanding of the dual nature of psychological distance in online reviewing behavior. Specifically, it suggests that, in addition to the well-known positivity bias, there is a negativity bias represented by a negative relationship between spatial distance and ratings for negative experiences. These findings are driven by spatial distance, allowing reviewers to overcome the need to protect their self-view, which is central to communicating word-of-mouth online. This study draws a broader picture of psychological distance in online reviewing behavior, connects self-enhancement theory and selfdistancing theory in an online context, and demonstrates how taking consumer behavior online gives rise to novel theoretical relationships differing from those established in an offline context. 


\section{References}

Angelis, M. D., Bonezzi, A., Peluso, A. M., Rucker, D. D., and Costabile, M. 2012. "On Braggarts and Gossips: A Self-Enhancement Account of Word-of-Mouth Generation and Transmission," Journal of Marketing Research (49:4), pp. 551-563 (doi: 10.1509/jmr.11.0136).

Arkin, R. M., and Maruyama, G. M. 1979. "Attribution, Affect, and College Exam Performance," Journal of Educational Psychology (71:1), pp. 85-93 (doi:10.1037/0022-0663.71.1.85).

Ayduk, O., and Kross, E. 2010. "From a Distance: Implications of Spontaneous Self-Distancing for Adaptive Self-Reflection," Journal of Personality and Social Psychology (98:5), pp. 809-829 (doi:10.1037/a0019205).

Babić Rosario, A., Sotgiu, F., De Valck, K., and Bijmolt, T. H. 2016. "The Effect of Electronic Word of Mouth on Sales: A Meta-Analytic Review of Platform, Product, and Metric Factors," Journal of Marketing Research, (53:3), pp. 297-318.

Bagozzi, R. P., Baumgartner, H., and Yi, Y. 1992. "Appraisal Processes in the Enactment of Intentions to Use Coupons," Psychology \& Marketing (9:6), pp. 469-486.

Barasch, A., and Berger, J. 2014. "Broadcasting and Narrowcasting: How Audience Size Affects what People Share,” Journal of Marketing Research (51:3), pp. 286-299.

Bhatia, S., and Walasek, L. 2016. "Event Construal and Temporal Distance in Natural Language," Cognition (152), pp. 1-8 (doi:10.1016/j.cognition.2016.03.011).

Bird, S., Klein, E., and Loper, E. 2009. Natural Language Processing with Python: Analyzing Text with the Natural Language Toolkit, O'Reilly Media, Inc.

Blaine, B., and Crocker, J. 1993. "Self-esteem and Self-Serving Biases in Reactions to Positive and Negative Events: An Integrative Review," in Self-Esteem, Springer, pp. 55-85.

Brown, J. D., Collins, R. L., and Schmidt, G. W. 1988. "Self-Esteem and Direct versus Indirect Forms of Self-Enhancement," Journal of Personality and Social Psychology (55:3), pp. 445-453 (doi:10.1037/0022-3514.55.3.445).

Bruehlman-Senecal, E., and Ayduk, O. 2015. "This too Shall Pass: Temporal Distance and the Regulation of Emotional Distress," Journal of Personality and Social Psychology (108:2), pp. 356375 (doi:10.1037/a0038324).

Brysbaert, M., Warriner, A. B., and Kuperman, V. 2014. "Concreteness Ratings for 40 Thousand Generally Known English Word Lemmas,” Behavior Research Methods (46:3), pp. 904-911 (doi:10.3758/s13428-013-0403-5). 
Carney T. 2019. How do I stop being asked for ratings and reviews?. URL: https://support.google.com/maps/thread/9957365/how-do-i-stop-being-asked-for-ratings-andreviews?hl=en (visited on 05/06/2021).

Correia, S. 2019. "REGHDFE: Stata module to perform linear or instrumental-variable regression absorbing any number of high-dimensional fixed effects," Statistical Software Components S457874, Boston College Department of Economics, revised 18 Nov 2019.

Daft, R. L., \& Lengel, R. H. 1986. Organizational Information Requirements, Media Richness and Structural Design. Management Science, (32:5), pp. 554-571.

Du, J., Rong, J., Michalska, S., Wang, H., and Zhang, Y. 2019. "Feature Selection for Helpfulness Prediction of Online Product Reviews: An Empirical Study,” PloS One (14:12), e0226902.

Feng, J., Li, X., and Zhang, X. 2019. "Online Product Reviews-Triggered Dynamic Pricing: Theory and Evidence," Information Systems Research (30:4), pp. 1107-1123 (doi:10.1287/isre.2019.0852).

Fujita, K., Henderson, M. D., Eng, J., Trope, Y., and Liberman, N. 2006. "Spatial Distance and Mental Construal of Social Events," Psychological Science (17:4), pp. 278-282 (doi:10.1111/j.14679280.2006.01698.x).

Hennig-Thurau, T., Gwinner, K. P., Walsh, G., and Gremler, D. D. 2004. "Electronic Word-of-Mouth via Consumer-Opinion Platforms: What Motivates Consumers to Articulate Themselves on the Internet?" Journal of Interactive Marketing (18:1), pp. 38-52 (doi:10.1002/dir.10073).

Hogg, M. K., and Michell, P. C. N. 1996. "Identity, Self and Consumption: C Conceptual Framework," Journal of Marketing Management (12:7), pp. 629-644.

Hu, N., Pavlou, P. A., and Zhang, J. 2017. “On Self-Selection in Online Product Reviews,” MIS Quarterly (41:2), pp. 449-471.

Huang, N., Burtch, G., Hong, Y., and Polman, E. 2016. "Effects of Multiple Psychological Distances on Construal and Consumer Evaluation: A Field Study of Online Reviews," Journal of Consumer Psychology (26:4), pp. 474-482 (doi:10.1016/j.jcps.2016.03.001).

Hutto, C. J., and Gilbert, E. 2014. "Vader: A Parsimonious Rule-Based Model for Sentiment Analysis of Social Media Text," Eighth International AAAI Conference on Weblogs and Social Media.

Kahn, J. H., Tobin, R. M., Massey, A. E., and Anderson, J. A. 2007. "Measuring Emotional Expression with the Linguistic Inquiry and Word Count," The American Journal of Psychology (120:2), pp. 263-286.

Kokkodis, M., and Lappas, T. 2020. "Your Hometown Matters: Popularity-Difference Bias in Online Reputation Platforms," Information Systems Research (31:2), pp. 412-430. (doi:10.1287/isre.2019.0895). 
Kross, E., and Ayduk, O. 2011. "Making Meaning out of Negative Experiences by Self-Distancing," Current Directions in Psychological Science (20:3), pp. 187-191.

Kross, E., and Ayduk, O. 2017. "Self-distancing: Theory, Research, and Current Directions," in Advances in Experimental Social Psychology (55), Elsevier, pp. 81-136.

Kross, E., Ayduk, O., and Mischel, W. 2005. "When Asking "Why” does not Hurt. Distinguishing Rumination from Reflective Processing of Negative Emotions," Psychological Science (16:9), pp. 709-715 (doi:10.1111/j.1467-9280.2005.01600.x).

Kross, E., Bruehlman-Senecal, E., Park, J., Burson, A., Dougherty, A., Shablack, H., Bremner, R., Moser, J., and Ayduk, O. 2014. "Self-Talk as a Regulatory Mechanism: How You Do It Matters," Journal of Personality and Social Psychology (106:2), pp. 304-324 (doi:10.1037/a0035173).

Leisch, F. 2006. “A Toolbox for k-Centroids Cluster Analysis,” Computational Statistics \& Data Analysis (51:2), pp. 526-544.

Maglio, S. J. (2020): “An Agenda for Psychological Distance apart from Construal Level,” Social and Personality Psychology Compass 14 (8) (doi:10.1111/spc3.12552).

Maglio, S. J., Trope, Y., and Liberman, N. 2013. "The Common Currency of Psychological Distance," Current Directions in Psychological Science (22:4), pp. 278-282 (doi:10.1177/0963721413480172).

Miller, G. A. 1995. "WordNet: A Lexical Database for English," Communications of the ACM (38:11), pp. 39-41 (doi:10.1145/219717.219748).

Mischkowski, D., Kross, E., and Bushman, B. J. 2012. "Flies on the Wall are Less Aggressive: SelfDistancing 'in the Heat of the Moment' Reduces Aggressive thoughts, Angry Feelings and Aggressive Behavior,” Journal of Experimental Social Psychology (48:5), pp. 1187-1191.

Moser, J. S., Dougherty, A., Mattson, W. I., Katz, B., Moran, T. P., Guevarra, D., Shablack, H., Ayduk, O., Jonides, J., and Berman, M. G. 2017. “Third-Person Self-Talk facilitates Emotion Regulation without Engaging Cognitive Control: Converging Evidence from ERP and fMRI," Scientific Reports (7:1), pp. 1-9.

Parkinson, C., Liu, S., and Wheatley, T. 2014. "A Common Cortical Metric for Spatial, Temporal, and Social Distance,” Journal of Neuroscience (34:5), pp. 1979-1987 (doi:10.1523/JNEUROSCI.215913.2014).

Pennebaker, J. W., Booth, R. J., Boyd, R. L., and Francis, M. E. 2015. Linguistic Inquiry and Word Count: LIWC2015, Austin, TX: Pennebaker Conglomerates (www.LIWC.net).

Picard, R. 2010. "ffGEODIST: Stata module to compute geographical distances," Statistical Software Components S457147, Boston College Department of Economics, revised 24 Jun 2019. 
Schmid, H. 1999. "Improvements in Part-of-Speech Tagging with an Application to German," in Natural Language Processing Using Very Large Corpora, Springer, pp. 13-25.

Schoenmueller, V., Netzer, O., and Stahl, F. 2020. "The Polarity of Online Reviews: Prevalence, Drivers and Implications," Journal of Marketing Research (57:5), pp. 853-877 (doi:10.1177/0022243720941832).

Sadiq, S.; Umer, M.; Ullah, S.; Mirjalili, S.; Rupapara, V.; Nappi, M. 2021. "Discrepancy Detection between Actual User Reviews and Numeric Ratings of Google App Store using Deep Learning," Expert Systems with Applications (Forthcoming).

Sedikides, C. 1993. "Assessment, Enhancement, and Verification Determinants of the Self-Evaluation Process," Journal of Personality and Social Psychology (65:2), pp. 317-338 (doi:10.1037/00223514.65.2.317).

Seih, Y.-T., Beier, S., and Pennebaker, J. W. 2017. "Development and Examination of the Linguistic Category Model in a Computerized Text Analysis Method," Journal of Language and Social Psychology (36:3), pp. 343-355.

Semin, G. R., Görts, C. A., Nandram, S., and Semin-Goossens, A. 2002. "Cultural Perspectives on the Linguistic Representation of Emotion and Emotion Events," Cognition \& Emotion (16:1), pp. 1128.

Semin, G. R., and Smith, E. R. 1999. "Revisiting the Past and Back to the Future: Memory Systems and the Linguistic Representation of Social Events," Journal of Personality and Social Psychology (76:6), pp. 877-892.

Shrauger, J. S. 1975. "Responses to Evaluation as a Function of Initial Self-Perceptions," Psychological Bulletin (82:4), pp. 581-596 (doi:10.1037/h0076791).

Stamolampros, P., and Korfiatis, N. 2018. "Exploring the Behavioral Drivers of Review Valence," International Journal of Contemporary Hospitality Management (30:10), pp. 3083-3099 (doi:10.1108/IJCHM-04-2017-0239).

Thelwall, M. 2017. "The Heart and Soul of the Web? Sentiment Strength Detection in the Social Web with SentiStrength," in Cyberemotions, Springer, Cham, pp. 119-134.

Trope, Y., and Liberman, N. 2010. "Construal-Level Theory of Psychological Distance," Psychological Review (117:2), pp. 440-463 (doi:10.1037/a0018963).

Trope, Y., Liberman, N., and Wakslak, C. 2007. “Construal Levels and Psychological Distance: Effects on Representation, Prediction, Evaluation, and Behavior," Journal of Consumer Psychology (17:2), pp. 83-95 (doi:10.1016/S1057-7408(07)70013-X). 
Vargo, C., Gangadharbatla, H., and Hopp, T. 2019. "eWOM across Channels: Comparing the Impact of Self-Enhancement, Positivity Bias and Vengeance on Facebook and Twitter," International Journal of Advertising (38:8), pp. 1153-1172 (doi:10.1080/02650487.2019.1593720).

Vincenty, T. 1975. "Direct and Inverse Solutions of Geodesics on the Ellipsoid with Application of Nested Equations," Survey Review (23:176), pp. 88-93.

Warriner, A. B., Kuperman, V., and Brysbaert, M. 2013. "Norms of Valence, Arousal, and Dominance for 13,915 English lemmas," Behavior Research Methods (45:4), pp. 1191-1207.

Weingarten, E., and Berger, J., 2017. "Fired up for the Future: How Time Shapes Sharing," Journal of Consumer Research (44:2), pp. 432-447 (doi:10.1093/jcr/ucx041).

White, R. E., Kuehn, M. M., Duckworth, A. L., Kross, E., and Ayduk, Ö. 2019. "Focusing on the Future from Afar: Self-Distancing from Future Stressors Facilitates Adaptive Coping," Emotion (19:5), pp. 903-916 (doi:10.1037/emo0000491).

Williams, L. E., Stein, R., and Galguera, L. 2014. "The Distinct Affective Consequences of Psychological Distance and Construal Level," Journal of Consumer Research (40:6), pp. 11231138 (doi:10.1086/674212).

Wojnicki, A. C., and Godes, D. 2017. "Signaling Success: Word of Mouth as Self-enhancement," Customer Needs and Solutions (4:4), pp. 68-82.

Yelp. 2021. Yelp Open Dataset. URL: https://www.yelp.com/dataset (visited on 05/06/2021).

Yin, D., Mitra, S., and Zhang, H. 2016. "Research Note-When do Consumers Value Positive vs. Negative Reviews? An Empirical Investigation of Confirmation Bias in Online Word of Mouth," Information Systems Research, (27:1), pp. 131-144.

Zhang, M., and Wang, J. 2009. "Psychological Distance Asymmetry: The Spatial Dimension vs. Other Dimensions," Journal of Consumer Psychology (19:3), pp. 497-507 (doi:10.1016/j.jcps.2009.05.001). 


\section{Appendix}

Table A1: Further Robustness Checks

\begin{tabular}{|c|c|c|}
\hline Concern & Dataset & Robustness Checks \\
\hline Scaling of our variables & TripAdvisor & $\begin{array}{l}\text { - Mean centering LN_TRAVEL_DIST and } \\
\text { LN_MONTH_DIFF }\end{array}$ \\
\hline $\begin{array}{l}\text { Loss of observations from } \\
\text { dropping all reviews with a } \\
\text { temporal difference greater than } \\
0\end{array}$ & TripAdvisor & $\begin{array}{l}\text { - Re-estimating our baseline model with a triple } \\
\text { interaction between } L N \_T R A V E L \_D I S T \text {, } \\
\text { NEGATIVITY and a binary variable indicating } \\
\text { whether MONTH_DIFF>0 }\end{array}$ \\
\hline $\begin{array}{l}\text { Rule out theoretical explanation } \\
\text { offered by Berger and } \\
\text { Weingarten (2017) }\end{array}$ & TripAdvisor & $\begin{array}{l}\text { - Add average arousal as a control variable after } \\
\text { determining it using the dictionary provided by } \\
\text { Warriner et al. (2013) }\end{array}$ \\
\hline $\begin{array}{l}\text { Inaccurate operationalization of } \\
\text { sentiment }\end{array}$ & TripAdvisor & $\begin{array}{l}\text { - Alternative operationalization using average } \\
\text { negativity score of all sentences as determined } \\
\text { by SentiStrength (Thelwall 2017) }\end{array}$ \\
\hline $\begin{array}{l}\text { Results confounded by } \\
\text { popularity difference between } \\
\text { locations and travel context }\end{array}$ & Yelp & $\begin{array}{l}\text { - Control for area's popularity based on hotel } \\
\text { reviews in that area (Kokkodis and Lappas } \\
\text { 2020) } \\
\text { - Allow for within-metropolitan-area variation in } \\
\text { traveling }\end{array}$ \\
\hline $\begin{array}{l}\text { Results confounded by self- } \\
\text { reported home locations }\end{array}$ & Yelp & $\begin{array}{l}\text { - Data-driven determination of a reviewer's usual } \\
\text { rating area based on: } \\
\circ \begin{array}{l}\text { At least } 50 \% \text { of all reviews made in } \\
\text { that area }\end{array} \\
\circ \quad \begin{array}{l}\text { At least three reviews posted in that } \\
\text { area }\end{array} \\
\circ \quad \begin{array}{l}\text { Day difference between date of first } \\
\text { and last review of at least } 360 \text { days }\end{array} \\
\end{array}$ \\
\hline $\begin{array}{l}\text { Estimation on a metropolitan } \\
\text { area level is too coarse }\end{array}$ & Yelp & $\begin{array}{l}\text { - Re-estimating the baseline model on the Yelp } \\
\text { data set while allowing for within-metropolitan } \\
\text { area travel }\end{array}$ \\
\hline
\end{tabular}

Note: All the robustness checks presented yield qualitatively unchanged results when estimating our baseline model. 
Table A2: Variables used for Clustering

- $\quad$ City (the city in which the restaurant is located)

- Metropolitan Area (the metropolitan area, where the restaurant is located)

- Number of Reviews (the number of reviews a restaurant has obtained)

- State (the state where the restaurant is located)

- Accepts Credit Cards*

- Parking Garage*

- Parking Street

- $\quad$ Parking Validated*

- Parking Lot*

- Parking Valet*

- $\quad$ Price $(\$, \$ \$, \$ \$$, or $\$ \$ \$$ )

- Good for Kids*

- Good for Dessert*

- Good for Latenight*

- Good for Lunch*

- Good for Dinner*

- Good for Breakfast*

- Good for Brunch*

- Attire (e.g., casual or dressy)

- Delivery*

- Good for Groups*

- Take Out*

- Wifi (no, free)

- Alcohol (full bar, beer and wine, none)

- Has TV*

- $\quad$ Noise Level (quiet, average, very loud)

- Outdoor Seating*

- Reservations*

- Table Service*

- Ambience Romantic*

- Ambience Intimate*

- Ambience Classy*

- Ambience Hipster*

- Ambience Divey*

- Ambience Touristy*

- Ambience Trendy*

- Ambience Upscale*

- Ambience Casual*

- Good for Dancing*

- Category 1 (e.g., Seafood, Italian, Traditional American)

- Category 2

- Category 3

Note: Dummy variables are marked by an asterisk. 


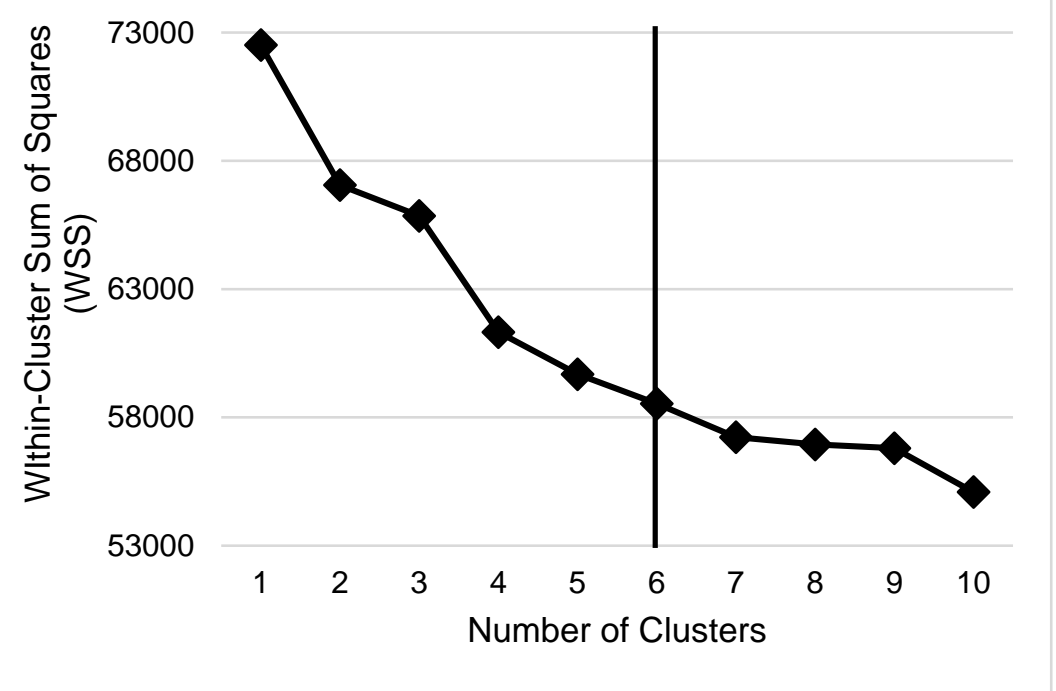

Figure A1: Scree Plot for Cluster Number Determination 